\title{
Perinatal Complications of Twin Deliveries at Jimma University Specialized Hospital, Southwest Ethiopia: A Facility-based Cohort Study
}

\author{
Temesgen Tilahun $^{1^{*}}$, Fitsum Araya ${ }^{2}$ and Gurmesa Tura ${ }^{2}$ \\ ${ }^{1}$ College of Medical and Health Sciences, Wollega University, P.O. Box: 395, Nekemte, Ethiopia \\ ${ }^{2}$ College of Public Health and Medical Sciences, Jimma University, Jimma, Ethiopia
}

\begin{tabular}{|c|c|}
\hline \multirow{10}{*}{$\begin{array}{l}\text { Twin pregnancy carries higher foetal and neonatal complications. This situation is worse in } \\
\text { Sub-Saharan Africa due to lack of well-equipped facilities. Studies on twin pregnancy and its } \\
\text { perinatal complications are limited in Ethiopia. Thus, this study aimed to fill this gap. A } \\
\text { hospital-based cohort study was conducted in Jimma University Specialized Hospital on } 144 \\
\text { twin deliveries and } 288 \text { singleton deliveries from December } 2012 \text { to November } 2013 \text { in } \\
\text { obstetrics ward of Jimma university specialized hospital. Data were collected through face-to- } \\
\text { face interview by using structured-questionnaire and analyzed by SPSS V.20.0. The relative } \\
\text { risks of twin deliveries were higher for the occurrence of low birth weight, need for neonatal } \\
\text { intensive care unit admissions, early neonatal deaths and preterm births as compared with } \\
\text { singleton deliveries. Unique foetal complications like both twin deaths, co-twin deaths, } \\
\text { discordant twin and gross congenital malformation were common in twin deliveries. In } \\
\text { conclusion, women with twin pregnancy were at a higher risk of ante-partum and intrapartum } \\
\text { foetal and neonatal complications. Therefore, care providers should give special attention for } \\
\text { the mother during pregnancy, labour and delivery, and both for the mother and her new born } \\
\text { during postpartum period. }\end{array}$} & Article Information \\
\hline & Received : 07-01-2015 \\
\hline & : 20-03-2015 \\
\hline & $\begin{array}{l}\text { Accepted : 26-03-2015 } \\
\text { Keywords: }\end{array}$ \\
\hline & Twin delivery \\
\hline & Perinatal complication \\
\hline & \\
\hline & \\
\hline & \\
\hline & \\
\hline
\end{tabular}

\section{INTRODUCTION}

Twin is a type of multiple birth in which the mother gives birth to two offspring from the same pregnancy. Its incidence is increasing over the world. Twin foetuses are either dizygotic or monozygotic. It can occur after assisted reproductive technology (ART) or spontaneously (Akinboro et al., 2008 and Dera et al., 2007).

Twin pregnancy continues to be a focus of interest all over the world. It is associated with increased risk of maternal and neonatal complications both in developed and developing countries. This is probably worse in subSaharan Africa where there may be lack of facilities to manage twin pregnancy and delivery and where poverty, ignorance, and harmful cultural beliefs and practices are still frequent. Available evidence also indicates that twin pregnancies are also associated with a number of financial, emotional, personal and social costs for their families and twins themselves. It accounts for at least $10 \%$ of perinatal mortality (Dera et al., 2007; Gessessew, 2007 and Abasiattai et al., 2010).

A number of unique complications develop in twin pregnancies. They include conjoined twinning, twin-totwin transfusion syndrome (TTTS), growth discordance, death of one or both foetus(es), congenital malformation, intrauterine growth restriction (IUGR) and monoamnionic placentation. Each of these is associated with increased perinatal mortality and morbidity (Cunningham et al.,
2010; Steven G. Gabbe et al., and Adams, 2007; Shepherd and Smith, 2011; Takae et al., 2011; Simpson, 2013; Breathnach and Malone, 2012; Mille et al., 2012 and Blickstein and Perlman, 2012).

Intrauterine foetal death (IUFD) of one twin foetus occurs approximately in 0.5 to $6.8 \%$ of twin pregnancies. Death of both twin foetuses can occur in about in $0.5 \%$ of twin pregnancies. Additional risks to the babies include intrauterine growth restriction and congenital abnormalities. Major malformations develop in $2 \%$ and minor malformations in $4 \%$ of twins than in singleton pregnancies (Cunningham et al., 2010 and Morin and Lim, 2011)

Twin pregnancy when compared with singleton pregnancy also carries higher foetal and neonatal complications like low birth weight, prematurity, still births, and neonatal deaths (Cunningham et al., 2010; Simpson, 2013; Morin and Lim, 2011; Ananth and Chauhan, 2012; Ibrahim et al., 2012; Steven and Frank, 2011; Abdulaziz, 2001; Glinianaia et al., 2013; Sikosana L. Majid, 2006).

\section{METHODS AND MATERIALS}

Study Design, Setting and Participants

Hospital-based prospective cohort study was conducted in Jimma University Specialized Hospital 
Temesgen Tilahun et alo,

(JUSH), which is located $346 \mathrm{kms}$ Southwest of Addis Ababa, the capital of Ethiopia. Jimma University Specialized Hospital is found in Jimma zone of Oromia regional state and one of the oldest teaching hospitals in the country. It gives services to people living in Jimma zone and serves as a referral hospital in the Southwest part of the country. It has also been serving as a clinical postgraduate specialty teaching hospital for Obstetrics and Gynaecology, Internal Medicine, Paediatrics and Child Health since 2005.

Twin pregnancies were considered as exposed and singleton pregnancies were considered as non-exposed for this study. Multiple outcomes on perinatal complications including from 28 weeks of pregnancy, labour and delivery, and after delivery until the time of discharge from hospital were considered.

\section{Sample Size and Sampling Techniques}

The sample size for this study was determined by using Epi-Info Version 7 by considering two-population comparisons of proportions based on the following assumptions. Foetal malpresentation was taken as one of the outcome variables (foetal complications). The proportion of mothers developing foetal malpresentation among exposed (twin deliveries) is assumed to be $16 \%$ $\left(p_{1}=0.16\right)$ and among non-exposed (singleton deliveries) is assumed to be $6 \%\left(p_{2}=0.06\right)$ (Obiechina, 2011). A level of confidence of $95 \%$ and power of $90 \%$ were considered. A ratio of 1:2 was used for the exposed to non-exposed. After adding $5 \%$ for non-responses and by Fleiss estimation, the final sample size became 144 exposed (twin deliveries) and 288 non-exposed (singleton deliveries), a total of 432 deliveries. By taking this study as open cohort, all twin deliveries were included in the study until the required sample was obtained, which took a year period from December 01, 2012 to November 30, 2013. For each twin delivery, two singleton deliveries happening just next to the twin delivery were taken as non-exposed. All twin pregnancies admitted to labour or maternity ward and terminated prior to gestational age of 28 weeks were excluded from this study. All mothers (both the exposed and non-exposed) were evaluate for their foetal well being by using ultrasound and their foetal condition were strictly followed from the time of admission to the labour ward to delivery. After delivery every newborn from exposed and non-exposed was assessed and strictly followed to the time of discharge from hospital to observe any neonatal complications.

\section{Data Collection Procedures}

A pre-tested structured questionnaire was developed after reviewing similar literatures for the data collection. The questionnaire, which was prepared in English, was translated in to Afan Oromo (regional language) and retranslated back to English by other people to maintain its consistency. Three Obstetrics and Gynaecology residents, one midwife nurse and two medical interns working in the labor ward were recruited, trained and completed the questionnaires. The diagnosis and management of the complications were a team approach (one obstetrics resident, one paediatrics resident, one midwife and one medical intern) and it was thought that no difference in the skills of the providers between the exposed and non-exposed that lead to observer bias. Training was given on the objective and relevance of the study, confidentiality of information, respondent's right, informed consent and techniques of interview. Basic
Sci. Technol. Arts Res. J., Jan-March 2015, 4(1): 134-138

socio-demography of the mother and past obstetric histories were collected at admission during history taking. The occurrences of any perinatal complications were observed by regular check up until the time of discharge from hospital. All completed questionnaires were reviewed each night and morning sessions were conducted every day with the data collectors to discuss on the problem encountered during data collection procedures.

\section{Data Processing and Analysis}

The collected data were entered to, cleaned and analysed by using SPSS for windows version 20.0. Descriptive statistics such as proportions means and standard deviations were determined to describe the study participants by cross-tabulating according to their exposure status. Relative Risks (RR) along with their 95\% confidence intervals $(\mathrm{Cl})$ were determined to measure the existence of significant associations between twin delivery and each perinatal complication by using chi-squared $\left(x^{2}\right)$ test, Fisher-Exact test was used when the assumption of the $x^{2}$-test was not fulfilled.

\section{Ethical Considerations}

Ethical clearance was obtained from the Ethics Review Committee of the College of Public Health and Medical Sciences of Jimma University. Written informed consent was also obtained from every study participant before the interview by explaining the objective of the study. All the information collected from the study participants were handled confidentially through omitting their personal identification, conducting the interview in private place and using the data for the research purpose only.

\section{RESULTS}

\section{Socio-Demographic Characteristics}

Most of the study population were $337(78.1 \%)$ Oromo, 303(70.1\%) Muslims, 431(99.8\%) married, 284(65.7\%) housewife $(64.6 \%$ vs. $66.3 \%), 178(41.2 \%)$ can't read and write, and $268(62 \%)$ residing out of Jima. Majorities of the deliveries were from the age group 228(52.8\%) $20-24$ years $(51.4 \%$ among twins vs. $53.5 \%$ among singletons) (Table 1).

\section{Perinatal Complications of Twin Delivery}

In this study there were 144 sets of twins (288 births) and 288 singleton births giving total of 576 births. The mean gestational age at delivery for twin and singleton deliveries were $35.1 \pm 2.5$ and $37.4 \pm 2 \quad(P$-value $=0.002)$ weeks respectively. The mean birth weight of twin births when compared with singleton counterpart was 2,546 \pm 666 vs. $3,106 \pm 561$ grams respectively $(P$-value $=0.001)$ (Table 2).

$57.7 \%$ of twin births have birth weight less than 2500 grams when compared with $10.7 \%$ of singleton births. $6.3 \%$ of twin births had low $5^{\text {th }}$ minute APGAR score when compared with $1 \%$ of singleton births (Table 3 ).

The risk of preterm delivery was about four times higher in the twin pregnancies when compared with singleton pregnancies (RR=3.73, 95\% Cl: $2.79,4.99)$. The risk of low birth weight was about two times $(R R=1.74$, $95 \% \mathrm{Cl}: 1.23,2.44)$ and the need for NICU admission was about four times ( $\mathrm{RR}=3.91,95 \% \mathrm{Cl}: 2.49,6.15)$ in twin pregnancies than in singleton pregnancies. The major indication for admission to NICU were low birth weight $69(76.7 \%)$ and preterm baby $50(55.6 \%)$ among twin births when compared with singleton births in which case 
Temesgen Tilahun et alo,

meconium aspiration syndrome $14(46.7 \%)$ was the major one. The risk of neonatal death was about three times higher in the twin pregnancies when compared with singleton pregnancies $(\mathrm{RR}=2.75,95 \% \mathrm{Cl}: 1.54,22.07)$.
Sci. Technol. Arts Res. J., Jan-March 2015, 4(1): 134-138

The major causes of neonatal deaths for twin births were prematurity $9(64.3 \%)$ and sepsis $4(28.6 \%)$ whereas in singleton births it was perinatal asphyxia (PNA) $1(100 \%)$ (Table 4).

Table 1: Socio-demographic characteristics of the study participants, Jimma University Specialized Hospital, Southwest Ethiopia, December 2012 to November 2013

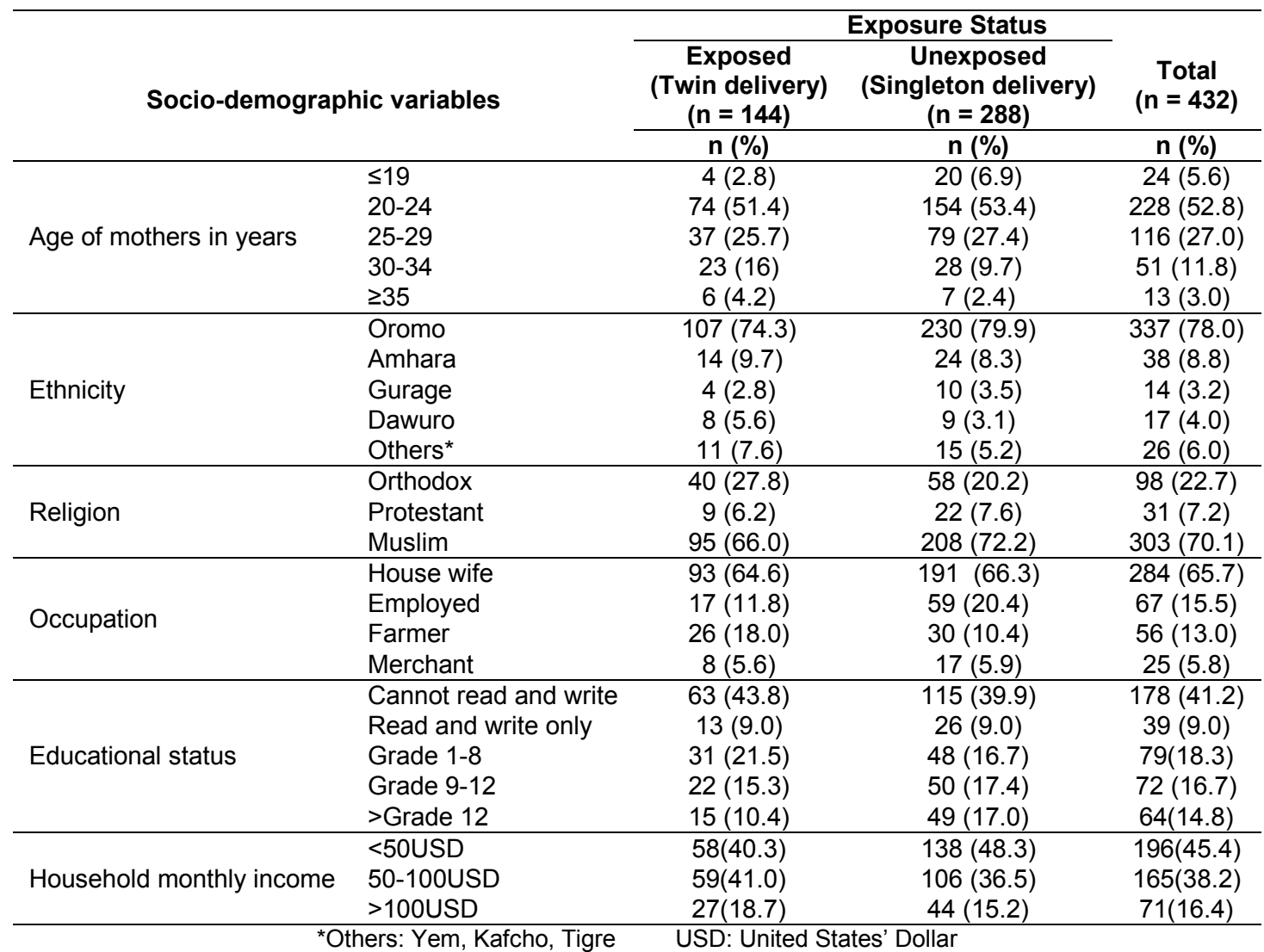

Table 2: Means of birth weight and gestational age among twin delivery versus singleton delivery at Jimma University Specialized Hospital, Southwest Ethiopia, December 2012 to November 2013

\begin{tabular}{cccc}
\hline \multirow{2}{*}{ Variable } & \multicolumn{2}{c}{ Exposure status } & \multirow{2}{*}{$\boldsymbol{P}$-value } \\
\cline { 2 - 4 } & Twin delivery $(\mathbf{n = 1 4 4 )}$ & Singleton delivery $(\mathbf{n = 2 8 8})$ & 0.002 \\
\hline Mean gestational age in weeks & $35.1 \pm 2.5$ & $37.4 \pm 2$ & 0.001 \\
Mean birth weight in grams & $2546 \pm 666$ & $3106 \pm 561$ & \\
\hline
\end{tabular}

Table 3: Perinatal outcome characteristics of twin delivery versus singleton delivery at Jimma University Specialized Hospital, Southwest Ethiopia, December 2012 to November 2013

\begin{tabular}{|c|c|c|c|c|}
\hline \multirow[b]{3}{*}{ Variable } & \multicolumn{4}{|c|}{ Exposure status } \\
\hline & \multicolumn{3}{|c|}{ Twin births } & \multirow[b]{2}{*}{$\begin{array}{c}\text { singleton births } \\
(\mathrm{n}=288) \\
\mathrm{n}(\%)\end{array}$} \\
\hline & $\begin{array}{c}1^{\text {st }} \text { twin births } \\
(n=144) \\
n(\%)\end{array}$ & $\begin{array}{c}2^{\text {nd }} \text { twin births } \\
(n=144) \\
n(\%)\end{array}$ & $\begin{array}{c}\text { Total twin births } \\
(n=288) \\
n(\%)\end{array}$ & \\
\hline \multicolumn{5}{|l|}{ Birth weight in grams } \\
\hline $1000-1499$ & $9(6.2)$ & $8(5.6)$ & $17(5.9)$ & $4(1.4)$ \\
\hline $1500-1999$ & $22(15.3)$ & $24(16.7)$ & $46(16)$ & $5(1.7)$ \\
\hline $2000-2499$ & $50(34.7)$ & $53(36.8)$ & $103(35.8)$ & $22(7.6)$ \\
\hline $2500-3500$ & $61(42.4)$ & $58(40.3)$ & $119(41.3)$ & $171(59.4)$ \\
\hline$>3500$ & $2(1.2)$ & $1(0.7)$ & $3(1.0)$ & $86(29.9)$ \\
\hline \multicolumn{5}{|l|}{ Low APGAR score $(<7)$} \\
\hline 1st minute & $40(31.0)$ & $58(46.7)$ & $102(40.0)$ & $87(35.5)$ \\
\hline 5th minute & $9(6.2)$ & $7(4.9)$ & $16(6.3)$ & $3(1.0)$ \\
\hline Need for resuscitation & $19(14.4)$ & $22(16.9)$ & $41(16.2)$ & $27(10.9)$ \\
\hline Need for NICU admission & $45(33.6)$ & $45(33.6)$ & $90(35.6)$ & $30(12)$ \\
\hline ENND & $7(5.4)$ & $7(5.6)$ & $14(5.5)$ & $1(0.4)$ \\
\hline Congenital malformation & $1(0.7)$ & $1(0.7)$ & $2(0.7)$ & $2(0.7)$ \\
\hline
\end{tabular}

ENND: Early Neonatal Death NICU: Neonatal Intensive Care Unit 
Table 4: Perinatal complications among twin versus singleton deliveries at Jimma University Specialized Hospital, Southwest Ethiopia, December 2012 to November 2013

\begin{tabular}{|c|c|c|c|c|c|}
\hline \multirow[b]{2}{*}{$\begin{array}{c}\text { Outcome } \\
\text { (Perinatal complications) }\end{array}$} & \multicolumn{2}{|c|}{ Exposure status } & \multirow[b]{2}{*}{$\begin{array}{c}\text { Total births } \\
(n=576) \\
N(\%)\end{array}$} & \multirow[b]{2}{*}{${ }^{*} \mathbf{R} R$} & \multirow[b]{2}{*}{$95 \% \mathrm{Cl}$} \\
\hline & $\begin{array}{c}\text { Twin births } \\
(\mathrm{n}=288) \\
\mathrm{N}(\%)\end{array}$ & $\begin{array}{c}\text { Singleton births } \\
(n=288) \\
N(\%)\end{array}$ & & & \\
\hline \multicolumn{6}{|l|}{ Preterm delivery $(<37$ weeks $)$} \\
\hline $\begin{array}{l}\text { Yes } \\
\text { No }\end{array}$ & $\begin{array}{l}109(37.8) \\
179(62.2)\end{array}$ & $\begin{array}{c}27(9.4) \\
261(90.6\end{array}$ & $\begin{array}{l}136(23.6) \\
440(76.4)\end{array}$ & 3.73 & $2.79,4.99$ \\
\hline \multicolumn{6}{|l|}{ Low birth weight (<2500 grams) } \\
\hline $\begin{array}{l}\text { Yes } \\
\text { No }\end{array}$ & $\begin{array}{l}166(55.9) \\
127(44.1)\end{array}$ & $\begin{array}{c}31(10.8) \\
257(89.2)\end{array}$ & $\begin{array}{l}197(34.2) \\
379(65.8)\end{array}$ & 1.74 & $1.23,2.44$ \\
\hline \multicolumn{6}{|l|}{$1^{\text {st }}$ minute low APGAR score $(<7)$} \\
\hline $\begin{array}{l}\text { Yes } \\
\text { No }\end{array}$ & $\begin{array}{l}102(54.0) \\
151(49.2)\end{array}$ & $\begin{array}{l}87(46.0) \\
156(50.8)\end{array}$ & $\begin{array}{l}189(32.8) \\
387(67.2)\end{array}$ & 1.21 & $0.84,1.74$ \\
\hline \multicolumn{6}{|l|}{ Need for NICU admission } \\
\hline $\begin{array}{c}\text { Yes } \\
\text { No } \\
\end{array}$ & $\begin{array}{c}90(75) \\
198(43.4)\end{array}$ & $\begin{array}{c}30(25) \\
258(56.6)\end{array}$ & $\begin{array}{l}120(20.8) \\
456(79.2)\end{array}$ & 3.91 & $2.49,6.15$ \\
\hline \multicolumn{6}{|l|}{ Neonatal death } \\
\hline $\begin{array}{c}\text { Yes } \\
\text { No }\end{array}$ & $\begin{array}{c}14(4.7) \\
274(95.3)\end{array}$ & $\begin{array}{c}1(0.7) \\
287(99.3)\end{array}$ & $\begin{array}{c}15(2.6) \\
561(97.4)\end{array}$ & 2.75 & $1.54,22.0$ \\
\hline
\end{tabular}

There were $15(5.6 \%)$ intrapartal foetal deaths among twin pregnancies when compared with $4(0.8 \%)$ intrapartal foetal deaths among singleton pregnancies. The stillbirth rate among twin delivery was 121.5 per 1000 deliveries.

Among unique complications of twin pregnancies there were $2(1.4 \%)$ both twin deaths, 31(21.5\%) co-twin deaths, $16(5.6 \%)$ discordant twin and $2(0.7 \%)$ congenital malformation i.e. spinal bifida and anencephaly.

In this study, foetal mal-presentations were more common among twin deliveries when compared with singleton deliveries. The foetal presentations in twin deliveries were $180(62.5 \%)$ cephalic, $100(34.7 \%)$ breech and $8(2.7 \%)$ transverse lie whereas in singleton deliveries cephalic, breech, and transverse lie accounted for 260 $(90.3 \%), 20(6.9 \%)$ and $8(2.8 \%)$ respectively. This made overall mal-presentation rate $37.4 \%$ in twin deliveries when compared with $9.7 \%$ singleton deliveries. $147(51 \%)$ and $141(49 \%)$ of twin births were males and females respectively when compared with 166(57.6\%) and $122(42.4 \%)$ of singleton deliveries which were males and females respectively.

\section{DISCUSSION}

The mean gestational age at delivery for twin and singleton deliveries were $35.1 \pm 2.5$ and $37.4 \pm 2(P$ value $=0.002$ ) weeks respectively and the mean birth weight of twin births when compared with singleton counterpart was $2,546 \pm 666$ vs. $3,106 \pm 561$ grams respectively $(P$-value $=0.001)$. These findings are supported by other studies. For instance, study in Niger Delta University Teaching Hospital Okolobiri, from January 1, 2007 to December 31, 2010 showed, the mean gestational age was $33.3 \pm 2.6$ weeks, and the mean foetal weight was $2.34 \pm 0.54 \mathrm{~kg}$; and according to a National Vital Statistics report from the USA in 2004 ,the average birth weights for twins, were 2,333 grams (Ibrahim et al., 2012 and Steven and Frank, 2011).

Twin pregnancy carries higher foetal and neonatal complications when compared with singleton pregnancy (Ananth Chauhan, 2012 and Smits Monden, 2011). According to this study, preterm delivery $(37.8 \%)$, the need for neonatal ICU admission (75\%), low birth weight
$(57.7 \%)$, low $1^{\text {st }}$ minute APGAR score $(54 \%)$, intrapartal foetal death $(5.6 \%$ vs. $0.8 \%)$, neonatal deaths $(4.7 \%)$ were significantly common among twin deliveries when compared with that of singleton deliveries. This finding is supported by other studies in Ethiopia and abroad. Studies in two referral hospitals of Ethiopia namely St. Paul's Hospital in Addis Ababa and Mekele zonal hospital in Tigray showed low birth weight was identified in $53.5 \%$ and $55.9 \%$ of twin births respectively. Another study in USA indicated that preterm delivery and low birth weight to occur in $59 \%$ and $57 \%$ respectively (Gessessew, 2007; Shepherd and Smith, 2011 and Korsak, 1989).

The stillbirth rate among twin delivery was 121.5 per 1000 deliveries. These findings are higher than Stillbirth rates from other reports like 18 in England, 94 in Tanzania, 91 per 1,000 twin births in Nigeria (Sikosana L. Majid, 2006 and Obiechina, 2011) which might be explained by the higher rates of unique complications to twinning in this study and our difference in perinatal care.

A number of unique complications develop in twin pregnancies (Cunningham et al., 2010; Steven G. Gabbe et al., M, Adams, 2007; Shepherd and Smith, 2011; Simpson, 2013; Breathnach and Malone, 2012; Mille et al., 2012; Blickstein and Perlman, 2012 and Morin and Lim, 2011). In our study there were $1.4 \%$ of both twin deaths, $21.5 \%$ of co-twin deaths, $5.6 \%$ of discordant twin and $0.7 \%$ of congenital malformation i.e. spinal bifida and anencephaly. The co-twin deaths and both-twin deaths were higher in this study both of which could be explained by the fact that majority of twin cases came from rural areas where they couldn't get ultrasound examination earlier.

The occurrence of mal-presentation is higher among twin deliveries when compared with singleton deliveries (Cunningham et al., 2010; Kullima et al., 2011 and Steven and Frank, 2011). In our study, considering presentations of both twins, overall mal-presentation rate was $37.4 \%$ in twin deliveries when compared with $9.7 \%$ in singleton deliveries. This finding is higher than findings of other authors (Kullima et al., 2011 and Obiechina, 2011).This might be one explanation for increased other perinatal complications in twin deliveries. 
Temesgen Tilahun et alo,

As policy and program implications, this study has come-up with high occurrence of perinatal complications during pregnancy, delivery and after delivery among both twin and singleton pregnancies suggesting the importance of skilled care at birth for every delivery. However, twin pregnancy has increased risk of the occurrence of fetal and neonatal complications during pregnancy, delivery and after delivery necessitating special care.

This study may have its own limitation in that all the estimates of relative risks were based on crude estimate and other possible confounding factors were not controlled. This was because of the large number of multiple outcomes considered for intervention purposes. Future studies may address this by doing multivariate analysis by focusing on some specific fetal and neonatal complications.

\section{CONCLUSION}

In the conclusion, despite the above limitation, this study found that foetuses and neonates from twin pregnancy were at a higher risk of perinatal complications during pregnancy, labour, delivery, and postpartum periods. Therefore, the care providers should give special attention during pregnancy, labour and delivery for the mother and postpartum both for the mother and her new born.

\section{Conflict of Interests}

The authors declare that they have no competing interests.

\section{Acknowledgements}

We would like to acknowledge Jimma University Specialized Hospital for funding this research project. Our sincere gratitude also goes to all supervisors, data collectors and study participants for their cooperation and support during the study period.

\section{REFERENCES}

Abasiattai, A.M., Aniefiok J. Umoiyoho., Ntiense M. Utuk., Dolapo G. Shittu (2010). Incidence and mode of delivery of twin pregnancies in Uyo, Nigeria. Nigerian Medical Journal 51(4): 170-172.

Abdulaziz, A.M. (2001). Epidemiology and Antenatal Complications of Twin Gestation: An 8-Year Review. Bahrain Medical Bulletin 23(2): 56-60

Akinboro, A., Azeez, M.A. and Akinboro A.A. (2008). Frequency of twinning in southwest Nigeria. Indian Journal of Human Genetics 14(2): 41-47.

Ananth C.V., Chauhan, S.P. (2012). Epidemiology of Twinning in Developed Countries. Seminars in Perinatology 36(3): 156-161.

Blickstein, I., Perlman, S., (2012). Single fetal death in twin gestations. Journal of Perinatal Medicine 0(0):1-5.

Breathnach. F.M., Malone, F.D. (2012). Fetal Growth Disorders in Twin Gestations. Seminars in Perinatology 36(3):175-181.

Cunningham F.G, Kenneth J. Leveno., Steven L. Bloom., John C. Hauth., Dwight J. Rouse., Catherine Y.
Sci. Technol. Arts Res. J., Jan-March 2015, 4(1): 134-138 Spong. (2010). Williams Obstetrics. $23^{\text {rd }}$ edition. USA: McGraw-Hil

Dera, A., Grzegorz H. Bręborowicz., Louis Keith (2007). Twin pregnancy- physiology, complications and the mode of delivery. Archives of Perinatal Medicine 13(3): 7-16.

Gessessew, A. (2007). Twin deliveries in a zonal hospital: ten years retrospective study. Ethiopian Medical Journal 45(1):55-59

Glinianaia, S.V., Rankin, J., Sturgiss, S.N., Ward Platt, M.P., Crowder, D., Bell, R. (2013). The North of England Survey of Twin and Multiple Pregnancy. Twin Research and Human Genetics 16(2):112-116.

Ibrahim, I., Oyeyemi, A., Obilahi, A. (2012). Twin pregnancies in the Niger Delta of Nigeria: a four-year review. International Journal of Women's Health 4: 245-249.

Korsak, V.S. (1989). Incidence and some perinatal problems of multiple pregnancies in a central referral hospital, Addis Ababa. Ethiopian Medical Journal 27(4): 217-221.

Kullima, A.A., Audu, B.M., Geidam, A.D. (2011). Outcome of twin deliveries at the University of Maiduguri Teaching Hospital: A 5-year review. Nigerian Journal of Clinical Practice 14(3):345-348.

Mille Jena., Suneet P. Chauhan., Alfred Z. Abuhamad, (2012). Discordant twins: diagnosis, evaluation and management. American Journal of Obstetrics and Gynecology 206(1):10-20.

Morin, L., Lim, K. (2011). Ultrasound in Twin Pregnancies. Journal of Obstetrics and Gynaecology Canada 33(6): 643-656.

Obiechina, N.J., Okolie, V.E., Eleje, G.U., Okechukwu, Z.C., Anemeje, O.A. (2011). Twin versus singleton pregnancies: the incidence, pregnancy complications, and obstetric outcomes in a Nigerian tertiary hospital. International Journal of Women's Health 3: 227-230.

Shepherd, L.J., Smith, G.N., (2011). Conjoined Twins in a Triplet Pregnancy: A Case Report. Case Reports in Obstetrics and Gynecology, 2011, 235873. doi: $10.1155 / 2011 / 235873$

Sikosana L. Majid. (2006). Prevalence and characteristics of mothers with multiple pregnancies and associated labour complications at Muhimbili National Hospital. Dar es Salaam Medical Students Journal 14(1): 10-13.

Simpson, L.L. (2013). Twin-twin transfusion syndrome. American Journal of Obstetrics and Gynecology 208(1): 3-18.

Smits, J., Monden, C. (2011). Twinning across the Developing World. PLoS ONE 6(9):e25239 doi:10.1371/journal.pone.0025239

Steven Frank (2011). Twin pregnancy: Prenatal issues.Uptodate. 19.3 version electronic material.

Steven G. Gabbe., Joe Leigh Simpson., Jennifer R. Niebyl., Henry Galan., Laura Goetzl., Eric, R.M., Jauniaux, and Mark Landon (2007). Obstetrics: Normal and Problem Pregnancies. $5^{\text {th }}$ edition. USA: Elsevier.

Takae, S., Izuchi, S., Murayama, K., Kondo, H., Kobayashi, Y., Ishizuka, B. (2011). Two cases of pregnancy involving conjoined twins, with details of management after opting for live birth. Journal of Obstetrics and Gynaecology Research 37(10): 1478-1483. 